\title{
EFFECT OF JOB'S TEARS STALK ADDITION IN PARTICLEBOARD BONDED WITH UREA-FORMALDEHYDE RESIN
}

\section{Oh YS}

Department of Forest Resources, College of Life and Applied Science, Yeungnam University, Gyeongsan 38541, Korea; skyu9765@naver.com

Submitted September 2019; accepted February 2020

Job's tears (Coix lacryma-jobi) stalk was used as a possible raw material for particleboard. A urea-formaldehyde (UF) resin was synthesised in the laboratory with resin solids at 50\% content as a particleboard binder. The physical characteristics of the synthesised UF resin were analysed for solids content, specific gravity, viscosity, gel time, $\mathrm{pH}$ and free formaldehyde content. The laboratory particleboards were made using Job's tears stalk and wood particles based on a Job's tears stalk oven-dry weight of $0,10,20,30$ and $40 \%$ with UF resin. The physical and mechanical properties of the particleboard were tested according to the ASTM D 1037-99 procedure. Internal bond, bending strength properties of the particleboards made using the UF resin decreased gradually with increasing Job's tears stalk content. However, the acceptable physical and mechanical properties of all particleboards showed that Job's tears stalk is a suitable raw material for manufacturing of particleboard.

Keywords: Coix lacryma-jobi, agricultural stalk, internal bond, bending strength

\section{INTRODUCTION}

Particleboard is a wood-based panel product used generally in the manufacture of furniture, cabinets, interior wall and floor underlayment in home construction. The low cost of raw materials such as wood particles and urea-formaldehyde (UF) resins makes it relatively cheap to produce wood products from particleboard. Particleboard can be readily manufactured using flax residues and other agricultural residues such as straw and cotton stalks (Bowyer \& Stockmann 2001). Sustainable agricultural residues are potential alternative renewable sources of raw materials for the manufacturing of reconstituted bio-based board products. The widespread availability of agricultural wastes has harnessed new profit in using agricultural fibres for worldwide panels industry because of their environmental and profitable advantages (Rowell et al. 1997). For employing other agro-based wastes for panel products, many global researchers have examined a wide range of sustainable renewable agricultural fibres such as particles and fibres of sugar cane bagasse, banana stem, kiwi branch, coffee husk, corn stalks, cotton stalks, rice husk, rice straw, sunflower stalk, chili pepper stalk and kenaf (Rowell et al. 1997, Oh \& Yoo 2011). Fabrication of low-density panels for middle layers using kenaf and three types of adhesives showed good results for internal bond, insulation and sound absorption (Sellers et al. 1993). Properties of the particleboards made with hemp shiv and wood particles are optimal at 1:1 ratio (Li et al. 2014).

Job's tears (Coix lacryma-jobi), also known as adlay and grows to approximately 1-3 $\mathrm{m}$ tall, is a broad-leaved and grain-bearing tropical plant. Job's tears is native to South-East Asia but is cultivated as an annual cereal crop in temperate regions. In the United States, it has naturalised in several states, e.g. Hawaii, Louisiana and Tennessee, and is cultivated in gardens throughout the world. Job' tears is considered a nutritious health cereal in many countries such as Brazil, China, India, Japan, Korea, Myanmar, Philippines, and Thailand (FAO 2019). Job's tears is a potential major crop for alternative or substitute to rice. Job's tears stalk can be used as an alternative fibre resource for commercial production of glued wood-based panel.

The objective of this study was to examine the properties of particleboard made from wood particles and Job's tears stalks. UF resin was formulated for bonding the particleboard in the 
laboratory. Physical and mechanical properties of particleboard were compared with those of panels made using different amounts of Job's tears stalks.

\section{MATERIALS AND METHODS}

\section{UF resin synthesis}

UF resin was formulated in the laboratory with a target resin solids level of $50 \%$ and a formaldehyde/urea (F/U) mole ratio of 1.15. To calculate the targeted resin solids levels, the charged urea solid value was taken, and the formaldehyde-derived solids were taken as the methylene group $\left(\mathrm{CH}_{2}\right)$ values, which were obtained by multiplying the charge weights by a factor of 14/30 (Oh 1999). The general procedure was similar to that outlined by $\mathrm{Oh}$ and Lee (2004). Firstly, $730.3 \mathrm{~g}$ of formaldehyde (F) solution (37\% concentration) was charged into a stirred reactor that was heated to $50{ }^{\circ} \mathrm{C}$. After the $\mathrm{pH}$ was adjusted to 7.7 with $6 \%$ sodium hydroxide solution, $269.7 \mathrm{~g}$ of urea $\left(\mathrm{U}_{1}\right)$ was added to bring the initial $\mathrm{F} / \mathrm{U}_{1}$ mole ratio to 2.0 over a period of $10 \mathrm{~min}$ while the reaction temperature was held at $70 \sim 80{ }^{\circ} \mathrm{C}$ with the heating control of the exothermic reaction. After the reaction temperature was increased gradually to $90{ }^{\circ} \mathrm{C}$, the $\mathrm{pH}$ of the reaction mixtures was decreased to 5.2 by using $8 \%$ sulfuric acid solution. This reaction temperature was maintained until the resin was polymerised in approximately $25 \mathrm{~min}$. When the reaction mixture had reached the desired viscosity, the $\mathrm{pH}$ was increased to 7.3 by adding $6 \%$ sodium hydroxide solution in order to end the polymerisation reaction, and $199.7 \mathrm{~g}$ of the second charge of urea $\left(\mathrm{U}_{2}\right)$ was added to give a final $\mathrm{F} /\left(\mathrm{U}_{1}+\mathrm{U}_{2}\right)$ mole ratio of 1.15 . The resin synthesis was completed by cooling to room temperature. The synthesised UF resin was stored for analysis and use.

\section{UF resin analysis}

The viscosity of the UF resin was measured using a viscometer, spindle number 1 at a rotation of $2.09 \mathrm{rad} \mathrm{s}^{-1}(20 \mathrm{rpm})$. Resin solids content was determined by heating $1 \mathrm{~g}$ of UF resin on an aluminum pan at $125^{\circ} \mathrm{C}$ for 2 hours. The $\mathrm{pH}$ was measured at $25^{\circ} \mathrm{C}$. Gel time required for the UF resin to harden was measured in a test tube at $100^{\circ} \mathrm{C}$, and the specific gravity was determined at $25^{\circ} \mathrm{C}$. Free formaldehyde content was measured using the hydroxylamine hydrochloride method (Walker 1964).

\section{Manufacture of particleboard}

Job's tears stalks were collected from the Gyeongsan region, South Korea. The Job's tears stalks particles (12-3.5 mesh) were dried to 4-5\% moisture content prior to use. Ash contents of the Job's tears stalk were determined according to TAPPI T 211 OM-85 (1992) test methods. A mixture of wood particles comprising $60 \%$ Terminalia brassii and 40\% Pinus densiflora (red pine) for the core layer was obtained from a commercial particleboard plant in South Korea. Laboratory particleboards were made using Job's tears stalk and wood particles based on the Job's tears stalk oven-dry weight of $0,10,20,30$ and $40 \%$. To obtain a better mixture of wood particles and Job's tears stalks, the two particle types were hand mixed and blended with the laboratory synthesised liquid UF resin in a rotary drum blender. The UF resin was applied using an air spray system at $172 \mathrm{kPa}$ (25 psi). Singlelayer homogeneous particleboards were then manufactured using the processing parameters shown in Table 1.

\section{Performance test of particleboard}

Test specimens were cut from boards and conditioned to equilibrium at a temperature of $20^{\circ} \mathrm{C}$ and $65 \%$ relative humidity before the test. Internal bond, modulus of elasticity (MOE) and modulus of rupture (MOR) were determined following ASTM D 1037-99 (2012). The panel water absorption and thickness swelling properties were observed after the 2 -and 24-hour soaking tests.

\section{Statistical analysis}

Panel property test results were analysed using the Statistical Analysis System programming package (SAS 1998, Release 6.10). Analysis of variance (ANOVA) was used to determine the differences within each panel type. Significant differences $(p<0.05)$ were further compared using $t$-test for the least significant differences (LSDs) from the SAS programming (Steel and Torrie 1980). 
Table 1 Particleboard manufacturing parameters

\begin{tabular}{ll}
\hline Panel dimensions & $250 \mathrm{~mm} \times 250 \mathrm{~mm} \times 6.3 \mathrm{~mm}$ \\
Mat moisture content & 8 to $9 \%$ \\
Wax and resin solids loading & 1 and $9 \%$ respectively, based on oven-dry wood weight \\
Target board density & $737 \mathrm{~kg} \mathrm{~m}^{-3}$ \\
Catalyst & None \\
Resin flow rate & $130 \mathrm{~mL} \mathrm{~min}^{-1}$ \\
Hot press temperature & $162{ }^{\circ} \mathrm{C}$ \\
Hot press times & $4 \mathrm{~min}$ \\
Replication & Four boards per condition (total of 20 boards) \\
\hline
\end{tabular}

\section{RESULTS AND DISCUSSION}

\section{Properties of UF resin}

The properties of UF resin are important parameters for their application in particleboard manufacture. The synthesised UF resin viscosity was $180 \mathrm{mPa} \cdot \mathrm{s}$, which was suitable for resin spray application with a compressed air sprayer (Table 2). Viscosity reflects the resin flow on wood particles under hot-pressing conditions. Resin flow is therefore a determining factor in the manufacture of good particleboard. As expected, the resin produced in this study had very low free formaldehyde content $(0.4 \%)$. Free formaldehyde content is an important parameter for panel emission quality. The resin had a $\mathrm{pH}$ of 7.5 , solid content of $50.5 \%$, and specific gravity of 1.19 . Typically, aqueous UF $50 \sim 65 \%$ solid solutions are usually suitable for bonding particleboard. Gel time of the UF resin was $31.8 \mathrm{~min}\left(\right.$ at $100^{\circ} \mathrm{C}$ ), which was relatively long due to the absence of any catalyst in the resin. Generally, gel time indicates the resin stability and cure speed in actual operations.

\section{Ash and pH of Job's tears stalk}

Job's tears stalk had an ash content of $9.4 \pm 0.15$ (standard deviation) at $600{ }^{\circ} \mathrm{C}$ and a pH of $6.3 \pm$

Table 2 Properties of the synthesised UF resin

\begin{tabular}{lc}
\hline Property & UF resin \\
\hline Solid content $(\%)$ & 50.5 \\
Specific gravity & 1.19 \\
$\mathrm{pH}$ & 7.5 \\
Gel time at $100^{\circ} \mathrm{C}(\mathrm{min})$ & 31.8 \\
Viscosity $(\mathrm{mPa} \cdot \mathrm{s})$ & 180 \\
Free formaldehyde $(\%)$ & 0.4 \\
\hline
\end{tabular}

0.08. Ash content and $\mathrm{pH}$ of Job's tears stalk were $9.4 \%$ and 6.3 respectively. Chemical compositions of Job's tears stalk probably influence the physical and mechanical properties of board (Rowell et al. 1997).

\section{Performance test of particleboard}

The particleboard densities in this study ranged from 713 to $723 \mathrm{~kg} \mathrm{~m}^{-3}$ (Table 3). The ANOVA results showed that the panel density was significantly $(p<0.05)$ affected by Job's tears stalk addition. The LSD test showed that the panel density was significantly $(\mathrm{p}<0.05)$ affected by Job's tears stalk particle content, with $100 \%$ wood particles (i.e. without addition of Job's tears stalk) being denser than $40 \%$ Job's tears stalk addition. However, the panels of Job's tears addition at $0,10,20$ and 30 had equivalent densities. The panel density variation was relatively constant in this study regardless of the Job's tears stalk content, suggesting that the operation to produce the panel mat was suitable. Uniform mats are essential for comparing the bonding performance of fabricated panels. Normally, panel density positively affects the strength properties of panels (Sellers et al. 1993).

Internal bond increased from $0.16 \mathrm{~N} \mathrm{~mm}^{-2}$ for $40 \%$ Job's tears stalk addition to $0.87 \mathrm{~N} \mathrm{~mm}^{-2}$ without addition of Job's tears stalk, i.e. as the Job's tears stalk content decreased (Table 3). The LSD test showed that internal bond was significantly affected by the Job's tears stalk content, which suggested that Job's tears stalk particles require larger resin loading to obtain the same internal bond as wood particles. Previous research reported that increasing resin loading generally improved the physical and mechanical properties of panels (Oh 2010). However, the panels exceeded the minimum strength requirements $\left(0.15 \mathrm{~N} \mathrm{~mm}^{-2}\right)$ for internal 


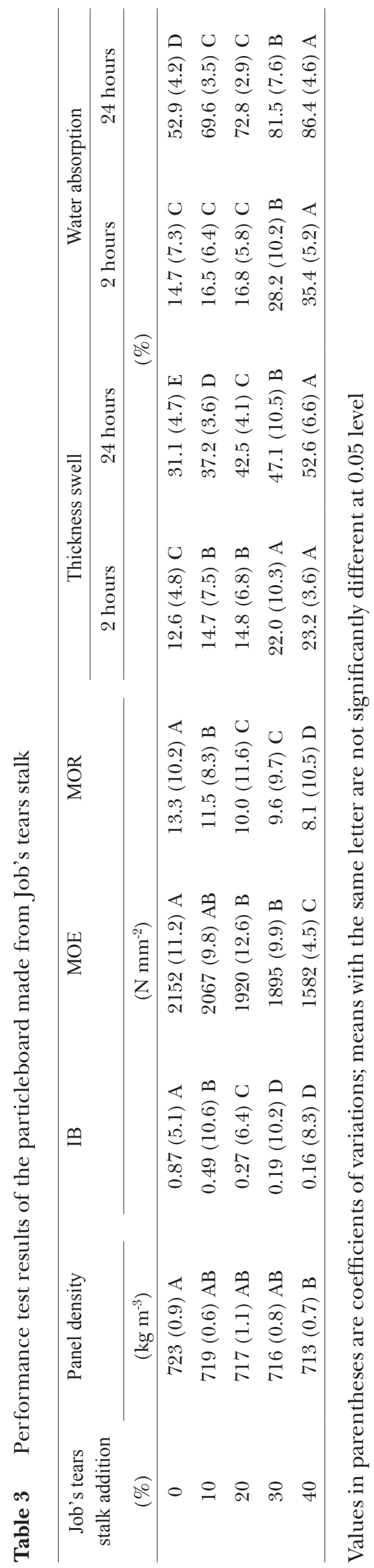


bond according to the Korean Standard KS F 3104 particleboard type 8.0 (KSA 2016).

MOE increased from $1582 \mathrm{~N} \mathrm{~mm}^{-2}$ for $40 \%$ stalk addition to $2152 \mathrm{~N} \mathrm{~mm}^{-2}$ for $0 \%$ stalk addition (Table 3). The LSD test for the MOE without stalk addition showed no significant variation from that of the $10 \%$ stalk addition. LSD test showed no significant differences for MOE between 10, 20 and 30\% Job's tears stalk addition. There were significant differences in MOE between 30 and $40 \%$ stalk addition.

MOR increased from $8.1 \mathrm{~N} \mathrm{~mm}^{-2}$ for $40 \%$ stalk addition to $13.3 \mathrm{~N} \mathrm{~mm}^{-2}$ for $0 \%$ stalk addition (Table 3). The LSD test showed without stalk addition, MOR differed significantly from $10 \%$ stalk addition. However, the MOR of $20 \%$ stalk addition was similar to that of $30 \%$ stalk addition. This difference was ascribed to the amount of particles used to produce the particleboards. Similar findings were previously reported for castor stalks and cotton stalks in particleboards (Grigorious \& Ntalos 2001, Guler \& Ozen 2004 respectively). However, all panels made from Job's tears stalk addition exceeded the minimum strength requirements $\left(8.0 \mathrm{~N} \mathrm{~mm}^{-2}\right)$ for MOR according to the Korean Standard KS F 3104 for particleboard type 8.0 (KSA 2016).

The thickness swelling values for all panels ranged from 12.6 to $23.2 \%$ for the 2-hour test and 31.1 to $52.6 \%$ for the 24 -hour test (Table 3 ). The LSD test for thickness swelling after the 24-hour water soak test showed that $0 \%$ stalk addition had significantly lower thickness swelling values than the rest of the stalk percentages.

Water absorption for all panels ranged from 14.7 to $35.4 \%$ for the 2-hour test and 52.9 to $86.4 \%$ for the 24-hour test (Table 3). LSD test for 24-hour water absorption showed that $40 \%$ stalk addition absorbed significantly more water after soaking for 24 hours than the other stalk addition, whereas $10 \%$ stalk addition and $20 \%$ stalk addition had similar 24-hour water absorption.

Dimensional stability test results showed that the thickness swelling and water absorption of the panel increased with increasing Job's tears stalk content. The differences in thickness swelling and water absorption observed in this study were ascribed to the presence of stalk particles in the boards, which can adversely influence their dimensional stability. The results are in agreement with the results previously reported by Grigorious and Ntalos (2001) and Guler and Ozen (2004).

\section{CONCLUSIONS}

Job's tears stalks were used as a raw material for particleboard manufacture. The performance test showed that the physical and mechanical properties of the particleboards produced decreased gradually with increasing Job's tears stalk content. Nevertheless, all boards made from Job's tears stalk addition in this study showed good physical and mechanical properties. The study showed that Job's tears stalk is a suitable raw material for particleboard manufacture.

\section{REFERENCES}

AStM (American Society for Testing and Materials). 2012. ASTM D 1037-99-Standard Test Methods for Evaluating Properties of Wood-Base Fiber and Particle Panel Materials. ASTM International, West Conshohocken.

Bowyer JL \& Stockmann VE. 2001. Agricultural residues an exciting bio-based raw material for the global panels industry. Forest Product Journal 51: 10-21.

FAO. 2019. Statistic of Agriculture and Forest Products. Food and Agriculture Organization of the United Nations. www.fao.org.

Grigorious AH \& NTAlos GA. 2001. The potential use of Ricinus communis L. (castor) stalks as a lignocellulosic resource for particleboards. Industrial Crops $\mathcal{E}^{\circ}$ Products 13: 209-218. https://doi.org/10.1016/ s00926-6690(00) 00078-9.

Guler C \& Ozen R. 2004. Some properties of particleboards made from cotton stalks. Holz als Roh- und Werk-stoff 62: 40-43. http://doi.org/10.1007/s00107-0030439-9.

KSA (Korean Standard Association). 2016. Korean Standard: KS F 3104 Particleboards. KSA, Seoul.

Li X, WAng S, Du G, Wu Z, Gong Y. 2014. Manufacturing particleboard using hemp shiv and wood particleboards with low free formaldehyde emission urea-formaldehyde resin. Forest Products Journal 64: 187-191. http://10.13073/FPJ-D-13-00073.

Он YS. 1999. Evaluation of melamine-modified ureaformaldehyde resin binders for particleboard. Forest Product Journal 49: 31-34.

Он YS. 2010. Effects of recycled fibre additions on highdensity fibreboard for laminated flooring bonded with phenol-formaldehyde resin adhesive. Journal of Applied Polymer Science 115: 641-645. http:/ / doi. org/10.1002/app.30435.

Он YS \& LEE JK. 2004. Evaluation of Korean softwood plywood bonded with urea-formaldehyde resin adhesive. Forest Product Journal 54: 77-80.

Он YS \& Yoo JY. 2011. Properties of particleboard made from chili pepper stalks. Journal of Tropical Forest Science 23: 473-477.

Rowell RM, Young RA \& Rowell JK. 1997. Paper and Composites from Agro-Based Resources. CRC Press Inc., Boca Raton. 
Sellers T Jr., Miller GD \& Fuller MJ. 1993. Kenaf core as a board raw material. Forest Products Journal 43: 69-71.

Steel RGD \& Torrie JH. 1980. Principles and Procedures of Statistics: A Biometric Approach. Second edition. McGraw-Hill Book Co., New York.
TAPPI. 1992. TAPPI Test Methods. TAPPI Press, Peachtree Corners.

WALker JF. 1964. Formaldehyde. Reinhold, New York. 